\title{
Rimski-Korsakov'un Şehrazat Senfonik Süiti’ndeki Fagot Sololarının İncelenmesi
}

\section{Research of Bassoon Solos in Rimsky-Korsakov's Scheherazade Symphonic Suite}

\section{Emre $\mathrm{HOPA}^{1}$ (D)}

'Doç. Dr., Anadolu Üniversitesi, Devlet Konservatuvarı, Müzik Bölümü, Eskişehir, Türkiye

\section{ORCID: E.H. 0000-0002-2264-9148}

\section{Sorumlu yazar/Corresponding author: Emre Hopa, \\ Anadolu Üniversitesi, Devlet Konservatuvarı, Müzik Bölümü, Eskişehir, Türkiye \\ E-posta/E-mail: ehopa@anadolu.edu.tr \\ Başvuru/Submitted: 28.10 .2019 Revizyon Talebi/Revision Requested: 11.12.2019 \\ Son Revizyon/Last Revision Received: 12.12.2019 \\ Kabul/Accepted: 27.12 .2019}

Atıf/Citation: Hopa, E. (2019). RimskiKorsakov'un Şehrazat Senfonik Süiti'ndeki fagot sololarının incelenmesi. Konservatoryum Conservatorium, 6(2), 105-116. https://doi.org/10.26650/CONS2019-0014 öz

Ulusal Rus müziğinin önde gelen bestecilerinden biri olan Rimski-Korsakov (18441908) öğretmen, editör ve teorisyen kimliği ile de müzik dünyasında yerini almış ünlü bestecilerden biridir. Rus beşlerinin en verimli ve çok yönlü üyelerinden birisi olarak bilinen Korsakov, Rus halk müziğine bağlılı̆ı, eserlerinde doğu ezgilerini kullanması ve kendine özgü orkestrasyon tekniği ile öne çıkmıştır. 1888 yılında bestelediği Şehrazat adlı senfonik süiti (Op.35) konusunu “Binbir Gece Masalları"ndan almaktadır. Eser, çerçeve hikâye olarak bilinen hikâye içinde hikâyeler şeklinde sunulmaktadır. Şehrazat'ın Sultan Şehriyar'a karşı stratejik oyunları ve bin bir gece boyunca süren hikâyesi anlatılmaktadır. Eserin ikinci bölümünde yer alan fagot soloları, ulusal ve uluslararası orkestra sınavlarında karşılaşılan en önemli eserlerden biri olma niteliği taşır. Soloların doğru bir biçimde yorumlanması bilgi birikimini, müzikaliteyi ve teknik beceriyi gerektirir. Bu çalışmanın amacı, Rimski-Korsakov'un Şehrazat adlı Senfonik Süiti hakkında genel bir bilgi verilmesi, fagot sololarının incelenmesi ve bu soloların yorumlanmasında karşılaşılan teknik ve müzikal zorluklar için çözüm önerilerinde bulunmaktır. Bu araştırma, Rimski-Korsakov'un Şehrazat adlı Senfonik Süiti hakkında literatür taraması yapılan nitel bir araștırmadır.

Anahtar Kelimeler: Rimsky-Korsakov, Şehrazat, Fagot

\section{ABSTRACT}

Rimsky-Korsakov (1844-1908), one of the leading composers of Russian national music, is one of the most famous composers with his identity as a teacher, editor, and theorist. Known as one of the most productive and sophisticated members of the Russian five, Korsakov came to the fore with his devotion to Russian folk music, the use of Eastern melodies in his works and his orchestration technique. The symphonic suite, Scheherazade (Op.35), which he composed in 1888, is based on "One Thousand and One Nights". The work is presented in the form of stories within the story which is known as a frame story. Scheherazade's strategic plans against Sultan Shahriar and her story that lasted for a thousand nights are narrated. The bassoon solos in the second movement of the work are one of the most important works encountered in national and international orchestral exams. A correct interpretation of solos requires knowledge, musicality and technical skills. This study aims to give general information about Scheherazade, to study the bassoon solos and to offer solutions for the technical and musical difficulties encountered in interpreting these solos. This research is a qualitative research doing a literature review about Rimsky-Korsakov's Scheherazade Symphonic Suite.

Keywords: Rimsky-Korsakov, Scheherazade, Bassoon 


\section{EXTENDED ABSTRACT}

Rimsky-Korsakov, one of the most famous composers of the Russian five, was born in 1844 and passed away in 1908. In 1962, he met Balakirev, the founder of the Russian five and studied composition with him. He was influenced by the orientalism movement and he incorporated different rhythm, melody, mode, harmony, and orchestration techniques in his works. In his works, he profited from Russian folk music and in his operas, he dealt with Russian-specific subjects. His symphonic suite, Scheherazade, which he composed in 1888, inspired by the tales of One Thousand and One Nights, is the most outstanding work of Russian orientalism. Today, the work which is considered as one of the most staged pieces is a work in which a tale is synthesized with music, and Eastern melodies are at the forefront. Although it was not composed as ballet music, it was choreographed and staged.

The work consists of 4 movements

1) Prelude: The Sea and Sinbad's Ship

2) Ballade: The Kalandar Prince

3) Adagio: The Young Prince and The Young Princess

4) Finale: Festival at Baghdad.

Korsakov's writing style, which reflects Eastern culture, has some similarities with Tamara, one of Balakirev's early works. In Korsakov's Scheherazade, it is known that he was influenced by a melody named “Akh, Dilav!" which is Balakirev's traditional Georgian song. The sense of rhythm and the descending movement of the melody in the second movement of the work show striking similarities with the structure of "Akh, Dilav" in Balakirev's draft book. One Thousand and One Nights, which has been translated into many languages and been an inspiration to film, opera, ballet and every branch of art, includes folk literature genres of wide geography. According to the story, when Sultan Shahriar finds out that his wife betrayed him, he executes her and begins to hate all women. He marries a different woman every day and executes her the next day. Scheherazade, the eldest daughter of one of the Sultan's officials, prepares a plan to save herself and other girls, and she marries Sultan Shahriar and begins to tell him a tale every night. However, every night, she ends the tale in its most captivating part and promises to complete the story the next night. Because the tales are very attractive and intriguing, Shahriar postpones Scheherazade's execution every day to hear more of the stories. At the end 
of the 1001st night, Scheherazade finishes her tales and says that she is ready for the punishment that will be given. Shahriar, on the other hand, is very impressed by these tales and abandons his brutal plan.

The bassoon solos in the second movement of the work are one of the most important works of national and international orchestral exams. Accurate interpretation of solos requires musicality and technical skill. The first of these solos starts in the second movement of the work at the 5th bar. It requires every sound to be shaped very carefully, and requires that articulations are heard. For the ups and downs in the melodies to be heard, it must be played flexibly adhering to the expression "ad libitum". The second solo of the same movement is a cadence in which technical and musical skills are at the forefront. It starts at the 323rd bar of the work. The solo, which starts as a lento in the same bar, ends as a ritardando at the end of the bar and returns to the first tempo in the second bar with the conductor's beat. It is based on the acceleration and retardation of the movement. This movement must be played steadily and unhurriedly. The melody repeats similarly 3 times.

This study is aimed to give general information about Rimsky-Korsakov's Symphonic Suite, Scheherazade, to examine the bassoon solos in the second movement of the work and to offer solutions for the technical and musical difficulties encountered in the interpretation of these solos. 


\section{Yöntem}

$\mathrm{Bu}$ araştırma, Rimski-Korsakov'un Şehrazat adlı Senfonik Süiti hakkında literatür taraması yapılan nitel bir araştırmadır. Konu hakkında görüşler belirtilerek betimleme yöntemi kullanılmıştır. Çalışma kapsamında besteci ve eser ile ilgili literatür taranmış; konu ile ilgili kitaplar, tezler ve makaleler incelenmiş ve fagot sololarının yorumlanmasına ilişkin çözüm önerileri sunulmuştur. Bu araştırmanın evrenini Rimski- Korsakov'un Şehrazat adlı senfonik süiti, örneklemini ise eserin ikinci bölümünde fagot için yazılan sololar oluşturmaktadır.

\section{Nikolay Andreyevich Rimski-Korsakov}

Rus beşleri'nin en genci Nikolay Andreyevich Rimski-Korsakov (1844-1908) Petersburg'daki Deniz Koleji'ni bitirmiş ve deniz subayı olarak Rus donanmasında görev almıştır. 1862'de Balakirev'le tanışan ve onunla kompozisyon çalışan bestecinin birinci senfonisi 1865 'de Balakirev yönetiminde seslendirilmiştir (Say, 1997, s. 439). Oryantalizm akımından etkilenerek Rus müziğine farklı ritim, melodi, mod, armoni ve orkestrasyon anlayışı getirmiştir. Eserlerinde sadece orijinal şark melodilerini kullanmakla yetinmeyerek kendine özgün Rus oryantalizmini de geliştirmiştir. Binbir gece masallarından esinlenerek bestelediği Şehrazat Senfonik Süiti buna en önemli örnektir. Diyatonik modları genellikle halk karakterlerinin tasvirlerinde kullanan besteci, fantastik masal karakterlerinde kendisinin geliştirdiği "asimetrik mod"u kullanmıştır. Tam ton ve yarım tonların sıralanmasıyla oluşturulan bu mod Rus Müziği teorisinde "Rimski-Korsakov Dizisi" ismini almıştır (Sultanova, 2012, s. 197).

İspanyol Kapriçyosu (1887), Şehrazat (1888) Senfonik Süiti, Rus Paskalya Uvertürü (1888) orkestra kurgusundaki ustalığına en güzel örneklerdir. 1896'da tamamladığı ve 1898'de ilk sahnelenişi yapılan Sadko adlı operası, müziksel kavrayışının olgun bir ifadesi olarak kabul edilir. Tipik özellikler taşıyan Kar Kızı ve Altın Horoz operaları Rusya dışındaki ülkelerde de ilgiyle karşılanmıştır (İlyasoğlu, 1999, s. 170).

\section{Şehrazat Senfonik Süiti}

Eser 1888 yılında bestelenmiştir. Binbir Gece Masalları'ndan üç hikâyeyi anlatır. Program müziği olarak (belli bir hikâyeyi anlatan enstrümantal müzik eseri) bestelenmiştir. Hikayeleri birbirine bağlayan iki ana tema bulunur. Bunlardan birisi kemanın seslendir- 
diği Şehrazat teması, diğeri ise bakır üflemeliler ile desteklenen görkemli Şehriyar temasıdır (Girgin, 2015, s. 4). İlk üç bölüm Binbir Gece Masalları'ndan alınmış üç hikâyeyi anlatır. "Bağdat’ta Şenlik" adını taşıyan dördüncü bölüm ise daha önceki üç bölüme konu olan hikayelerin birleștirilerek bir kaleydeskop mantığı ile harmanlanmış şeklidir (Girgin, 2015, s. 14). Bale müziği olarak bestelenmemesine rağmen ilk kez 4 Haziran 1910 tarihinde Michel Fokine tarafından koreografisi yapılmış ve Paris’teki Opera Garnier'de sahnelenmiştir (Rimski-Korsakov, 1942).

Korsakov "My Musical Life" başlıklı biyografisinde Şehrazat Senfonik Süiti'nin Arap gecelerinden konusunu almış olduğunu; bölünmüş, bağlantısız bölümler ve betimlemelerden oluştuğunu belirtmiştir. Korsakov, bölümleri birleştirmek için kemana yazdığ1 kısa soloların Şehrazat'ı temsil ettiğinden de bahsetmiş̧tir (Rimski-Korsakov, 1942, s. 292).

Rimski-Korsakov, Şehrazat adlı eserini 1888 yılında kaleme almaya başlamıştır. Bu süreçte Alexander Borodin'in ani ölümü ile yarıda kalan ve dört perdelik Prens Igor Operası'nı tamamlama görevini de üstlenmiştir. 1883 yılında Mily Balakirev'in asistanı olarak Court Capella'ya başvuru yapması ile beraber Balakirev'in eski çalışmalarını düzenlemek ve gözden geçirmek için oldukça fazla zaman harcaması, bestelemedeki verimini önemli bir şekilde düşürmüştür. Korsakov'un Doğu kültürünü yansıtan yazım stilinin ilham kaynağı Prens Igor'un "Poloveç Dansları" olarak bilinmesine rağmen, ses atmosferinin yapısı itibariyle Balakirev'in ilk eserlerinden biri olan "Tamara"dan da esinlendiği görülmektedir (Van Gansbeke, 2012, s. 166).

Binbir Gece Masalları'na bakıldığında masallar “çerçeve hikâye” tekniği ile anlatıcıya sunulmuştur. Ana karakter Şehrazat, güçlü bir sultan olan Şehriyar'a karşı stratejik bir oyun sergiler ve bin bir gece boyunca sürecek olan masallar anlatmaya başlar. Korsakov'un yazdığ birinci bölümün giriş kısmında kısaca işlenen konu işte bu Şehrazat masalıdir (Girgin, 2015, s. 110).

Eser 4 bölümden oluşur:

1) Prelüde: Deniz ve Sinbad'ın Gemisi

2) Ballade: Prens Kalender'in Öyküsü

3) Adagio: Genç Prens ve Prenses

4) Finale: Bağdat’ta Şenlik 
Birinci bölümde müzik, Şehriyar Sultan'1 anlatan güçlü ve enerjik tema ile başlar, bunu solo keman tarafindan seslendirilen Şehrazat teması izler. Şehrazat teması, gemici Sinbad'ın firtınalı bir havada Kral Mihriyan'ın ülkesine gitmesini ve limanda karşılaştığı bir Hintli dervişin öyküsünü anlatmaktadır. İkinci bölüm kemanın Şehrazat teması ile başlar, arkasından fagot ana temayı çalar. Prens Kalender haydutların eline düşmüş ancak ormana kaçarak kurtulmuştur. Müzik, onun ormanda yeraltındaki kötü ruhların ülkesine sığınmasını ve bu ruhlar tarafından maymun kılığına sokulup Çin'e kaçırılmasını anlatmaktadır. Üçüncü bölümde, Basora ülkesinin sultanının erkeklerden nefret eden kızı Cemile, yakışıklılığını duyduğu Mısırı İbrahim el Hasib’e aşık olmuştur. İbrahim de kızın resmini bir kitapta görüp onu sevmiştir. Müzik, İbrahim'in bin bir zorluğa katlanarak Basora'ya gelişini ve iki gencin evlenip mutlu olmalarını anlatmaktadır. Dördüncü bölüm, türlü maceralar sonrası Sinbad'ın Bağdat'a dönüşü ve şenliklerle karşılanışını canlandırılmaktadır. Ancak, Sinbad Bağdat'ta çok kalmayarak tekrar denize açılmıştır. Müzik, geminin korkunç bir firtınada batışını; ama Sinbad'ın, Şehrazat'ın öykülerini sürdürebilmesi için kurtarılışını anlatmaktadır (Durusu, 2019).

Korsakov, Şehrazat adlı eserini bestelerken Balakirev'in "Akh, Dilav!" adlı melodisinden esinlenmiştir. Şehrazat'ın ikinci bölümündeki ritim anlayışı ve melodinin inici hareketi, Balakirev'in taslak kitabındaki "Akh, Dilav" yapısı ile çarpıcı bir benzerlik göstermektedir (Issiyeva, 2018, s. 3).

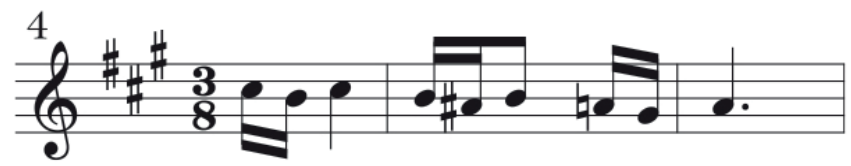

Şekil 1: Balakirev'in taslak kitabından "Akh, Dilav”, 4-6. ölçüler (Issiyeva, 2018, s. 4)

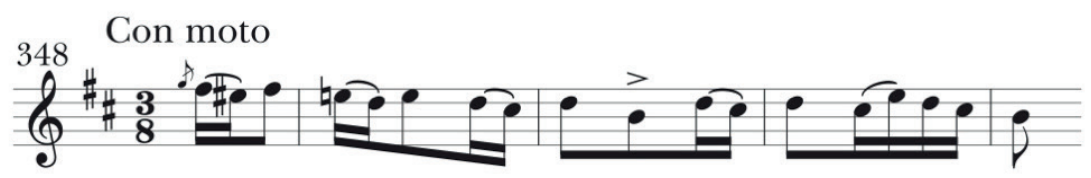

Şekil 2: Rimski-Korsakov, Şehrazat, 2. Bölüm, 348-351. ölçüler (Issiyeva, 2018, s. 4) 


\section{Binbir Gece Masalları}

Binbir Gece Masalları, diğer adı ile Arap Geceleri; hikâye, masal, destan, menkıbe ve fıkraları bir araya toplayan, eski Hint edebiyatında başka örneklerine de rastladığımız "çerçeveli hikâye"ler tipinde ve tekniğinde bir Arapça külliyattır. Antoine Galland'ın Fransızca'ya çevirisinden sonra Avrupa'da tanınmaya başlayan bu eser, Arap edebiyatı kadar, dünya edebiyatının da malı olan bir eser hâline gelmiştir (Tülücü, 2004, s. 1). Dünya edebiyatında adından çokça söz edilen, özellikle yazmaları Arapça olan ve birçok dilde çevirisi yapılan, film, opera, bale ve sanatın her dalına ilham kaynağı olan Binbir Gece Masalları, geniş bir coğrafyanın halk edebiyatı türlerini içine alan geniş bir külliyattır. Bu külliyatta, masal, efsane, halk hikâyesi, fikra türlerinin yanı sıra, halk mimarisi, halk müziği, tarih, coğrafya bilimlerine sunulan bilgiler de bulunmaktadır. Binbir Gece Masalları incelendiği zaman kahramanların adlarından olayların geçtiği coğrafyaya, yaşanılan sosyal hayattan masalların konularına kadar, özellikle Arap ülkeleri ile İran ve Mısır adlarının ön plana çıktığı görülmektedir (Nazlı, 2011, s. 16).

Binbir Gece Masalları'nın konusunun kadınların ihanetiyle ilgili olduğu düşünülmektedir. Ancak bu konu bin bir gece anlatılacak olan masallar için bir kurgu niteliği taşımaktadır. Külliyatta birden fazla türde anlatı bulunduğundan dolayı, konusu tek bir olay üzerine değildir. Binbir Gece Masalları, birbirinden farklı konuları anlatmaktadır. Bunlar; kadın ve erkek ilişkileri, dinî bilgi ve telkinler, tarihi bilgiler ile hikayelerin yazıya geçirildiği dönemin siyasal ve sosyal olaylarıdır (Nazlı, 2011, s. 23-24).

Birleştirici hikâyeye göre Şehriyar adındaki sultan karısının kendisini aldattığını öğrenince deliye döner ve yanındakilerle birlikte eşinin canını alır. Bugünden sonra bütün kadınlara karşı nefret beslemeye başlayan Şehriyar, her gün farklı bir kadınla evlenerek onu ertesi gün öldürtür. Bu durum yeni bir gelin adayı kalmayıncaya kadar böyle devam eder. Vezirin büyük kızı Şehrazat kendini ve başka kızları kurtarmak için bir plan hazırlar ve babasına sultanla evlendirilmesi için baskı yapar. Vezir en sonunda buna razı olur ve kızını Sultan Şehriyar ile evlendirir. Şehriyar ile evlenen Şehrazat ona her gece bir masal anlatmaya başlar. Ancak her gece masalı en heyecanlı yerinde kesen Şehrazat bir sonraki gece hikâyeyi tamamlayacağına dair söz verir. Masallar çok çekici ve merak uyandırıcı olduğu için Şehriyar hikayelerin devamını duymak uğruna Şehrazat'ın idamını her gün erteler. Bin birinci gecenin sonunda Şehrazat masallarını bitirir ve artık kendisi için verilecek cezaya hazır olduğunu söyler. Şehriyar ise bu masallardan çok etkilenerek kişiliğinde bir değişim yaşar ve acımasız planını uygulamaktan vazgeçer (Girgin, 2015, s. 4). 


\section{Fagot Sololarının İncelenmesi}

Şehrazat Senfonik Süiti’nin ikinci bölümü fagot repertuvarı açısından önemli iki soloyu içerir. $\mathrm{Bu}$ sololardan ilki eserin ikinci bölümünün 5. ölçüsünde başlar ve 3/8'lik metrik yapıdadır (Şekil 3). Temposu andantino (andante'den biraz daha hızlı) olarak belirtilen solonun capriccioso (canlı ve serbestçe) ve quasi recitado (kısmen resitativ gibi) ifadesiyle çalınması istenmiştir. Yorumcunun her sesi büyük bir titizlikle şekillendirmesini ve artikülasyonları net bir biçimde duyurmasını gerektirir. Dolce espressivo (tatlı ve dokunak11 bir şekilde) ifadesi yorumcudan nüans ve artikülasyon becerisi talep eder. Yorumcunun melodilerdeki iniş-çıkışları ve zıtlıkları duyurabilmesi için "ad libitum" (isteğe bağlı) ifadesine bağlı kalarak esnek bir şekilde çalması gerekir. Bu nedenle orkestra şefinden fagot solosunu takip ederek yaylı çalgıların ses girişlerini vermesi beklenir. Çarpma notaların kendinden sonra gelen seslerle uyum içinde çalınması önem arz eder. Bu notaların seslere başlangıç notası olması nedeniyle amacının süsleme olduğu unutulmamalı ve hız1 çalınmasından kaynaklanacak ses patlamalarının önüne geçilmelidir. Solonun ilk on ölçüsü birbirine benzer notalara sahip, ancak zit karakterler yansıtan iki müzik cümleciğinden oluşur. İlk cümlecik basit ve kibar bir karaktere sahipken, diğer cümlecik artikülasyonların değişmesi ile beraber daha kararlı ve agresif bir karaktere bürünür. 5. ölçüdeki si notası iki cümlecik arasındaki bağlantıyı kurar ve melodinin akıcılığına yardımcı olur. 10. ölçüde önel vuruşla başlayan cümle birbirine zıt iki karakteri barındırır. İkinci cümlecik bağlı, aksanlı ve özellikle üçleme notaların vurgulanması ile ilk cümleciğe zıtlık yaratır. Solonun A harfine bağlanan ölçüsü ritardando (gecikerek) ile ilk tempoya bağlanır.

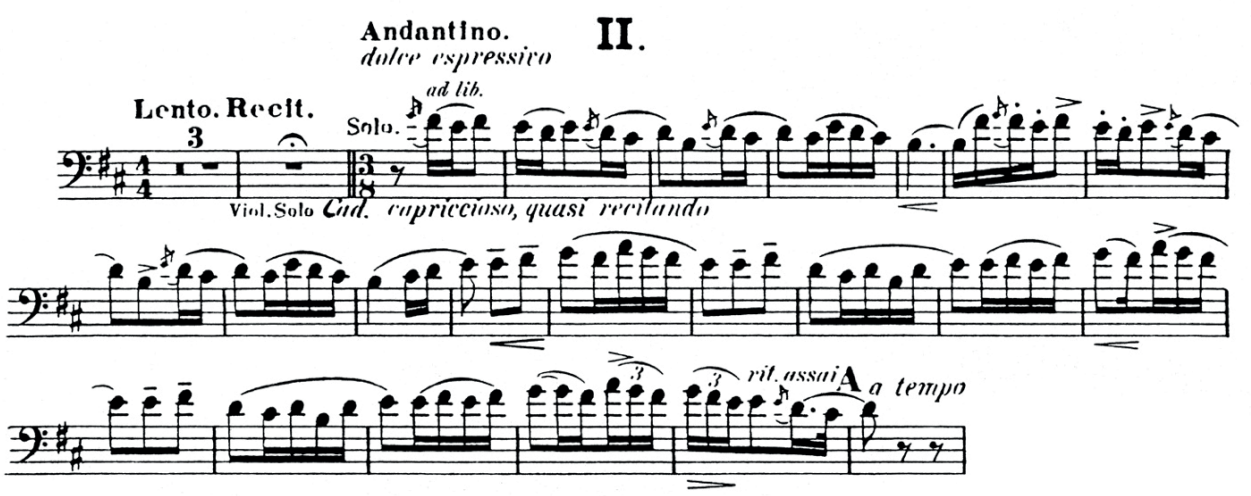

Şekil 3: Rimski-Korsakov, Şehrazat Senfonik Süiti Op. 35.

1. fagot partisi / 2. bölüm, 5-26. ölçüler arası (Rimski-Korsakov, 1888). 
Şekil 4'de Şehrazat Senfonik Süiti Op. 35'in 2. bölümündeki 5-26. ölçüler arasında yer alan 1. fagot partisi için çalışma önerisi yer almaktadır. Şekilde melodinin sürekliliğini ve bütünlüğünü sağlayan temel yapının ilerleyişi sunulmaktadır. Solonun öğrenilmesi sürecinde çarpmaların, bağlı ve vurgulu notaların bir arada kullanılması gerekliliği melodinin bütünlüğünü bozabilir. Melodinin esnek yapısı ve değişen artikülasyonların kullanımı çalgıya üflenen havanın sürekliliğine zarar verebilir. Bu nedenle müzik cümlesinin bölünmeden çalınması önem kazanır. Dr. Brett van Gansbeke'nin internet sitesinde bu solo için benzer bir çalışma önerisi de bulunmaktadır. Ancak, nüans ve artikülasyon belirteçleri bakımından farklılık göstermektedir (Van Gansbeke, 2019).

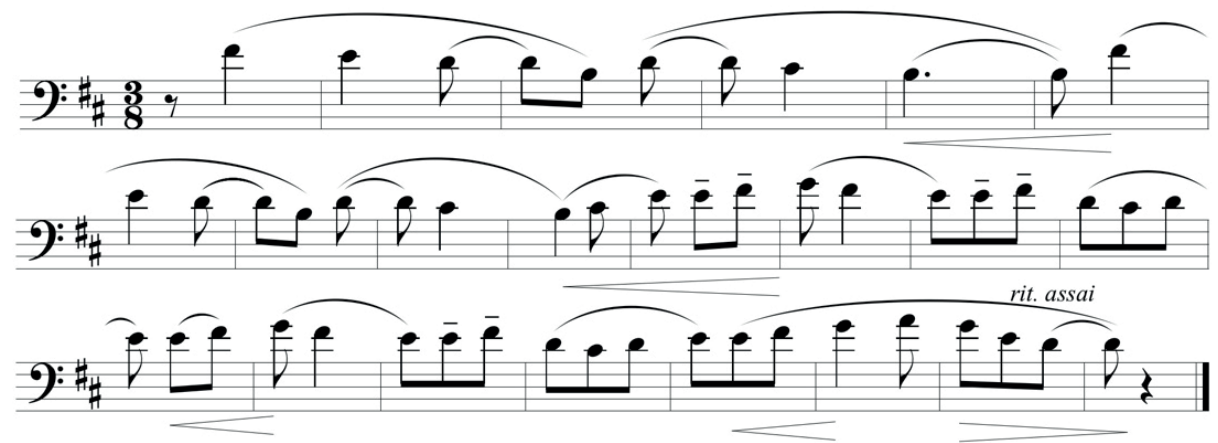

Şekil 4: Rimski-Korsakov, Şehrazat Senfonik Süiti Op. 35

1. fagot partisi / 2. bölüm, 5-26. ölçüler arası, çalışma önerisi.

Bölümde yer alan diğer fagot solosu teknik ve müzikal becerinin ön planda olduğu bir kadansdır (Şekil 5). Eserin 323. ölçüsünde başlar. Hız terimi moderato assai’dir (tam olarak orta hızda) ve recitative (konuşur gibi) bir yapıdadır. Aynı ölçü içerisinde lento olarak başlayan solo ölçünün sonunda ritardando olarak biter ve ikinci ölçüde şefin vuruşuyla ilk tempoya geri döner. Hareketin hızlandırılması ve geciktirilmesi üzerine kurulmuş bir yapıdadır. Bu hareketin kararlı ve telaşsız olarak çalınması önem arz eder. Melodi benzer şekilde $3 \mathrm{kez}$ tekrar eder. 


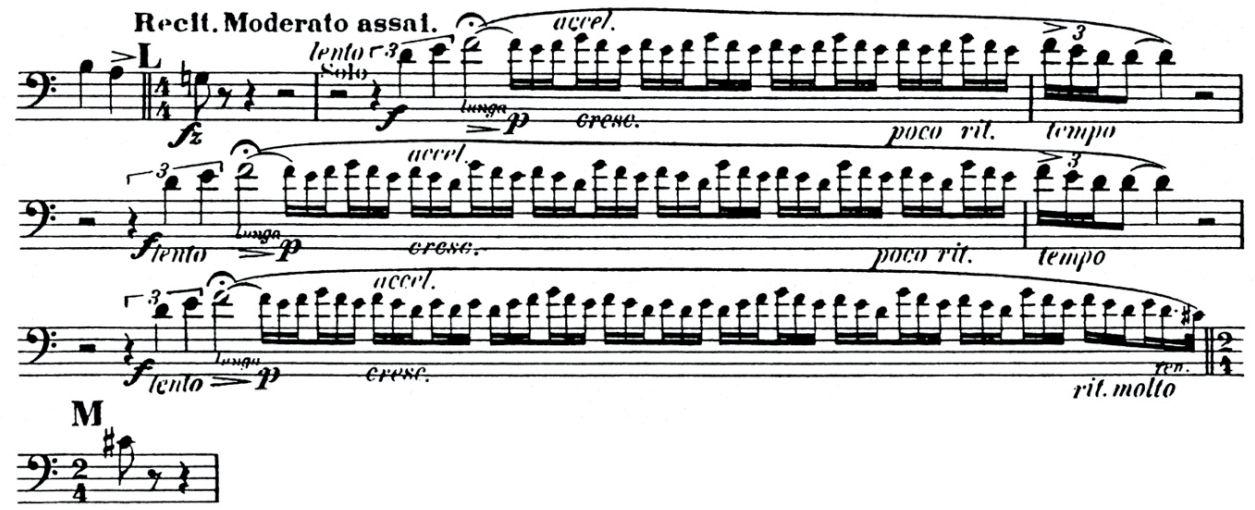

Şekil 5: Rimski-Korsakov, Şehrazat Senfonik Süiti Op. 35.

1. fagot partisi / 2. bölüm, 323-331. ölçüler aras1 (Rimski-Korsakov, 1888).

Fagotun üçüncü oktavındaki re, mi, fa ve sol notalarının perde geçişleri ardışık olmayan parmak hareketleriyle gerçekleşir. Bu perdelerin birbirleriyle bağlantıları parmakların senkronize bir şekilde hareketi ile mümkündür. Bu bağlantı aynı zamanda çalgıya aktarılan havanın sürekliliği ile de ilişkilidir. Kadansın forte (kuvvetli) nüansında başlayıp fa notasında decrescendo (ses yoğunluğunun azaltılması) yapması ve sonrasındaki ölçüye kadar crescendo (ses yoğunluğunun arttırılması) yapması hava akışının sürekliliğinin önemini vurgulamaktadır. Aynı ölçü içerisindeki tempo, nüans değişiklikleri ve bu değişikliklerin birbirleriyle bağlantıları seslerin akıcılığının sağlanmasında ve kadansın şekillenmesinde büyük rol oynar. Şekil 6'da kadansın rahatça çalınabilmesi için çalışma önerileri sunulmaktadır. 40 ila 90 metronom aralığında tekrar edilmesi önerilmektedir.

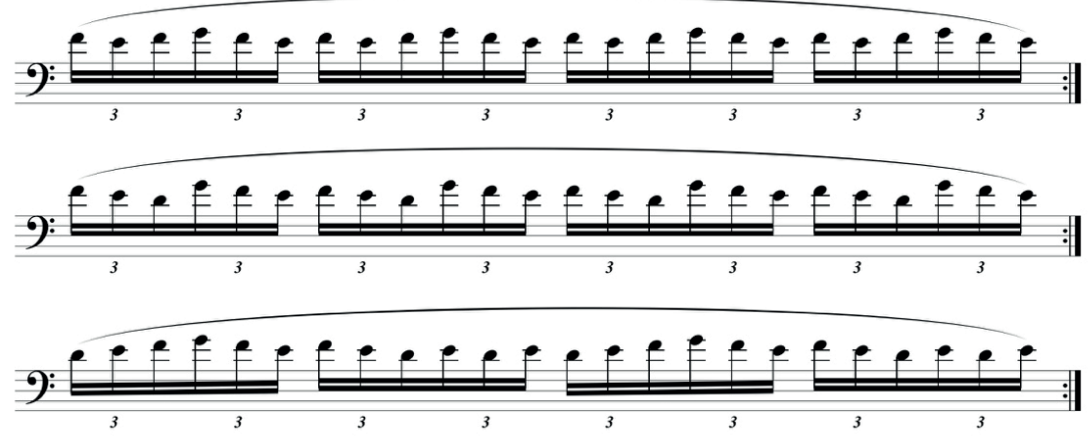

Şekil 6: Rimski-Korsakov, Şehrazat Senfonik Süiti Op. 35.

1. fagot partisi / 2. bölüm, 323-331. ölçüler arası, çalışma önerisi. 
David W. Oyen, “An Examination of Published Orchestral Excerpt Study Materials for Bassoon and Contrabassoon" adlı çalışmasında Korsakov'un Şehrazat adlı eserinin fark11 edisyonlardaki yazımlarına dikkati çekmiştir (1998). Yazar araştırmasında aynı eserin farklı edisyonlarındaki müzik terimlerini, işaretleri ve artikülasyonları incelemiştir. Edisyonlardaki yazım farklılıklarının sonucunda yorum farklılıklarının da ortaya çıkması kaçınılmazdır.

Eserin yayımlanmış edisyonları:

1) Rimski-Korsakov, N. Scheherazade. First Bassoon Part. New York: Kalmus, n.d.

2) Stadio, C. (1932) Passi Difficili e “A Solo” per Fagotto, Milan: Ricordi, 1954 reprint.

3) Kessler, C. (1947) Bassoon Passages. Books I and II. New York: Belwin, Inc.

4) Dherin, G. (1948-1954) Traits Difficiles, Tires d,oeuvres symphoniques et dramatiques. Vol.1-11. Paris: Leduc.

5) Angerhöfer, G. (1955) Orchesterstudien für Fagott. Heft 10, Russische und Sowjetische Meister. Leipzig: Hofmeister.

6) Righini, F. (1971) Il Fagotto in Orchestra. Milano: Published by Author.

7) Bolfan, M. (1980) Orkestarske Studije za Fagot. Knjazevac, Karadordeva (Yugoslavia): Izdavca organizacija.

8) Kolbinger, K.and Alfred Rinderspacher (1992) Orchester Probespiel, Fagott/Kontrafagott. Frankfurt: Peters.

\section{Sonuç}

Rimski-Korsakov'un 1888 yılında Binbir Gece Masalları'ndan esinlenerek bestelediği Şehrazat Senfonik Süiti, fagot repertuvarı açısından en göze çarpan eserlerinden biridir. Eserin ikinci bölümünde yer alan fagot soloları, ulusal ve uluslararası orkestra sınavlarında karşılaşılan en önemli eserlerden biri olma niteliği taşır.

Günümüzde en çok sahnelenen eserlerden biri olan Şehrazat, masalın müzikle sentezlendiği ve Doğu ezgilerinin ön planda olduğu bir çalışmadır. Rus oryantalizminin en göze çarpan eseri olma niteliği taşır. Bale müziği olarak bestelenmemesine rağmen koreografissi yapılmış ve sahnelenmiştir. Bölünmüş, bağlantısız bölümler ve betimlemelerden oluşmaktadır. Besteci, bölümleri birleştirmek için kemana yazdığı kısa soloların Şehrazat'1 temsil ettiğinden bahsetmiştir. 
Şehrazat Senfonik Süiti'nin ikinci bölümü fagot repertuvarı açısından önemli iki soloyu içerir. Bu sololardan ilki eserin ikinci bölümünün 5. ölçüsünde başlar. Melodilerin sürekliliği bakımından seslerin titizlikle şekillendirilmesini gerektirir. Çarpmaların, bağlı ve vurgulu notaların bir arada kullanılması önem arz eder. "Ad libitum" ifadesine bağlı kalınarak müzikal esnekliği şart koşar. Aynı bölümün diğer fagot solosu teknik ve müzikal becerinin ön planda olduğu bir kadanstır. Eserin 323. ölçüsünde başlar. Hareketin hızlandırılması ve geciktirilmesi üzerine kurulmuş bir yapıdadır. Bu hareketin kararlı ve telaşsız olarak çalınması önem arz eder.

Finansal Destek: Yazar bu çalı̧̧ma için finansal destek almamıştır.

\section{Kaynakça}

Durusu, Y. (2019, Eylül 11). Rimsky-Korsakov Şehrazad'ının hikâyesi. Erişim Adresi: http://mozartcultures.com/ Rimsky-korsakov-sehrazadinin-hikayesi/

Girgin, M. (2015). N. R. Korsakov “Şehrazad” senfonik süiti op. 35: Orkestra şefliği açısından teknik ve müzikal değerlendirme. (Yayımlanmamış Yüksek Lisans Tezi). Dokuz Eylül Üniversitesi Güzel Sanatlar Enstitüsü, İzmir.

Issiyeva, A. (2018). Nikolay Rimsky-Korsakov and his orient. Princeton University Press. DOI:10.23943/princeton/ 9780691182711.003 .0004

İlyasoğlu, E. (1999). Zaman içinde müzik (8. bs). İstanbul: Remzi Yayınevi.

Nazlı, A. (2011). Binbir Gece Masalları'nın Anadolu Türk masallarına etkileri üzerine bir araştırma. (Yayımlanmamış Doktora Tezi). T.C. Selçuk Üniversitesi Sosyal Bilimler Enstitüsü, Konya.

Oyen, D. W. (1998). An examination of published orchestral excerpt study materials for bassoon and contrabassoon, (Doctor of Music, Ohio State University, Ohio). Retrieved from https:/etd.ohiolink.edu/!etd.send_ file? accession $=$ osu $1302107909 \&$ disposition=inline

Rimsky-Korsakov, N. A. (1888). Şehrazat Senfonik Süiti Op.35. Boca Raton, FL: E.F. Kalmus. 2002.

Rimsky-Korsakov, N. A. (1917). Last of the great traditional composers of Russia. The Lotus Magazine, 9(3), 136-138.

Rimsky-Korsakov, N. A. (1942). My musical life. In C. van Vechten (Eds.), New York, USA: Alfred A. Knopf Publication.

Say, A. (2000). Müzik tarihi (3. bs). Ankara: Müzik Ansiklopedisi Yayınları.

Sultanova, A. (2012). Rus beşlerinin eserlerinde oryantalizm akımı. İdil Sanat ve Dil Dergisi, 5(1), 189-197. http:// dx.doi.org/10.7816/idil-01-05-12

Tülücü, S. (2004). Binbir Gece Masalları üzerine. Atatürk Üniversitesi İlâhiyat Fakültesi Dergisi, 22, 1-53.

Van Gansbeke, B. (2012). The orchestral bassoon: A pedagogical web site for bassoonists, (Doctor of Music, Indiana University, Bloomington). Retrieved from https://scholarworks.iu.edu/dspace/bitstream/handle/2022/14463/ vangansbeke_brett_2012.pdf?sequence=1\&isAllowed $=\mathrm{y}$

Van Gansbeke, B. (2019, Eylül 30). Pedagogy, II. "The Kalendar Prince”-M. 5 to rehearsal a Scheherazade, OP. 35, Nikolai Rimsky-Korsakov. Erişim Adresi: http:/www.orchestralbassoon.com/scheherazade-mvt-2-solopedagogy 